that we just have not got enough people who can man it. If you recognise that the large proportion of injuries in sport 3 do not require specific sports knowledge, but can be dealt with perfectly well by competent casualty officers - surely $\stackrel{0}{\circ}$ the first way of dealing with the situation is to get a decent casualty service in this country? This would benefit not $\overrightarrow{\vec{F}}$ only sportsmen, but indeed the whole population. Having gone on from that, you then want to improve the interest $\stackrel{\oplus}{+}$ and capacity of people dealing with rheumatological problems and orthopaedic problems at Clinic Hospital level $\stackrel{D}{C}$ possibly perhaps by removing from them the very heavy work loads that they have at the moment. A very large $\frac{}{\bar{F}}$ proportion of cases can be dealt with perfectly adequately at hospital, if the hospital services are good enough. I think $\frac{\bar{v}}{\vec{D}}$ the great mistake you all make in this country, putting back my International hat, is to try and set up, where you have $\stackrel{\odot}{\mathcal{Q}}$ got a National Health Service, a service for sportsmen, outside it. If you then graft on the specialist service to cope with \& the technopathies of which Dr. Sperryn has spoken, then you can provide, throughout the Country, a properly based $\vec{A}$ National Health Service, which will sort your athletes out, as well as everybody else. This is after all what happens in the German Democratic Republic, which is perhaps the best organised of all the sports medical set-ups in the whole $\vec{\omega}$ world. They have special rehabilitation centres for athletes who require this, but, I venture to suggest that such ${ }^{\circ}$ rehabilitation centres might possibly be found in England if you look hard enough. The service in the German $\frac{0}{6}$ Democratic Republic is based on their National Health Service, and, it can be equally well and efficiently based on ours $?$ if people get their facts right to start with. The evidence is there, people will not see it.

MISS SUE LIVINGSTON: Could I, perhaps, ask Dr. Cussen if there are any plans in the future, if there is anything planned in the way of special training courses in Sports Medicine, by the Institute?

DR CUSSEN: Our last one was motor racing, and then we had one on drowning, and then a most interesting one on $\frac{D}{2}$ association football by Neil Phillips; we have had three or four of those. They are always advertised.

DR H. ROBSON: Have the proceedings been published?

DR CUSSEN: I cannot tell you that.

\title{
CHAIRMAN'S CLOSING REMARKS
}

Ladies and Gentlemen I am supposed to be summing up, but I feel that you, between yourselves, have very largely summed up.

If I may give my own personal impression for what it is worth - it seems to me that the wide picture that the $\frac{0}{5}$ speakers have painted has been reduced to a not so wide discussion on individual differences from the floor. This makes it clear how unco-ordinated Sports Medicine is, in this country, and also how much overlap there is of first class 3 expertise. I am very interested, and rather amazed that nobody has taken up the point before, that the Sports Council, which does, and is increasingly doing, a great deal of work, as shown by that list of pseudo para-medical investigations, how duplication of good work occurs, I could give you a B.A.S.M. programme almost identical. What an extraordinary

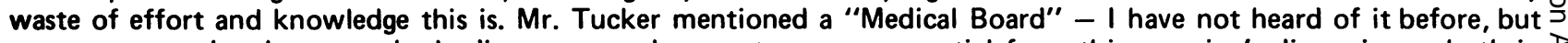
some co-operation between the bodies concerned seems to appear essential from this morning's discussion - both in $\frac{7}{0}$ general and in detail. We have been asked by Mr. Bissell and other people "can we help?" Of course we can help but nobody knows in what direction to go. This is where I would like to come back to the Sports Council, because as Dr. $N$ Williams pointed out - here is a government organisation, sponsored by government money, staffed by government people; these are the people who should be helping the various bodies concerned, who are trying to do their work ${ }_{N}$ without the facilities, or the financial ability to do so. If something like this had come out of this morning, I should be $\omega$ delighted. The C.C.P.R. in their new shape and form might be able to help co-ordination between the far too many? bodies dealing with Sports Medicine, provide some central post box to say the least of it - and from that a great dealo could come. We have heard of the setting up of standards in this particular interest (I would rather call it interest than a $\mathbb{\Phi}$ speciality) and $I$ am sure this is a very great move forward; it gives the subject a beginning, and it is very much a beginning. It is extraordinary that we have worked for 12 years now, and we are still floundering round in a very $\underline{0}$ amateur way, but I think the time has come in our organisation when the subject must be organised, or it will just go on $\frac{\vec{D}}{\mathbb{D}}$ floundering for ever, and we will sink lower in the International League Table. Perhaps you think I have been rather $\stackrel{\cap}{\stackrel{D}{\oplus}}$ pretentious, $I$ found it a most stimulating morning - it simply shows what a vast amount still remains to be done, and $I \stackrel{\odot}{\circ}$ think there are enough people in this room to achieve it, but they cannot achieve it running around in different $\bar{Q}$ directions. If nobody else said so, perhaps you will forgive me that I have, and I believe these people present here can 8 make something within the national ambit of Sports Medicine. There is a wealth of talent to call on of people who wish? 
to do so, and are very willing to help.

It seems to me there is a great deal of ground that we have just not had time to cover, but I think we have opened it up enough, I hope, to stimulate a little interest, and an overall desire in everybody to make this a combined set-up, worthy of the name of British Sport, and British Medicine. Thank you all very much.

A short time after this Symposium, our President received a communication.

December 18th, 1974

Institute of Sports Medicine, Ling House, 10 Nottingham Place, LONDON W1M 4AX

To Lord Porritt

From P. Sebastian

"I expect you will have heard from Lord Luke by now that the Board of Management of the Institute, while agreeing with our endeavours to pursue avenues for closer liaison between B.A.S.M. and I.S.M., has decided in favour of our continued separate existance."

VOL IX, No. 1, PROC. "FUTURE OF SPORTS MEDICINE"

ALPHABETICAL INDEX - MAIN SPEAKERS

BROWNING, G. G. Answering Sport's Needs - The B.A.S.M.'s viewpoint

CUSSEN, D. J. Answering Sport's Needs - The viewpoint of the Institute of Sports Medicine

KANE, J. E. Some Academic Aspects - A Physical Education viewpoint

NEWTON, D. R. L. Some Academic Aspects - Consultant Training

NICHOLS, P. J. R. Some Academic Aspects - The new Diploma in Rehabilitation Medicine

OWEN, J. R. Sports Problems - The British Olympic Association's viewpoint

PORRITT, Lord Chairman's opening remarks

PORRITT, Lord Chairman's closing remarks

SAYER, C. Sports Problems - The Sports Council's viewpoint

WILLIAMS, J. G. P. Answering Sport's Needs - Foreign precedents

\section{ALPHABETICAL INDEX - PARTICIPANTS IN DISCUSSION}

Name

BISSELL, S. J.

BROWNING, Dr. G. G.

CARRUTHERS, Dr. M.

CUSSEN, Dr. D. J.

HAWKES, Dr. J.

LIVINGSTON, Suzan

NEWTON, Dr. D. R. L.

NICHOLS, Dr. P. J. R.

\section{Page}

43

43

39

44

42

44

33

42
Name

Page

PORRITT, Lord

ROBSON, Dr. H. E.

ROSE, S. S.

STREET, Marion

THOMAS, A.

TUCKER, W. E.

WATTS, J.

WILLIAMS, J. G. P. 